\title{
The Crystal Structure of a Hyperthermophilic Archaeal TATA-box Binding Protein
}

\author{
Brian S. DeDecker ${ }^{1}$, Ronan O'Brien², Patrick J. Fleming ${ }^{1}$ \\ James H. Geiger ${ }^{1}$, Stephen P. Jackson ${ }^{3}$ and Paul B. Sigler ${ }^{1 *}$
}

${ }^{1}$ Department of Molecular Biophysics and Biochemistry and the Howard Hughes

Medical Institute

${ }^{2}$ Department of Chemistry

Yale University, JWG 421

P.O. Box 208114, New

Haven, CT 06511-8114, USA

${ }^{3}$ Wellcome/CRC Institute

Tennis Court Road, and

Department of Zoology,

Cambridge University,

Cambridge, CB2 1QR, UK
This study analyzes the three-dimensional structure of the TATA-box binding protein (TBP) from the hyperthermophilic archaea Pyrococcus woesei. The crystal structure of $P$. woesei TBP (PwTBP) was solved at 2.2 $\AA$ by X-ray diffraction and as expected from sequence homology ( $36 \%$ to $41 \%$ identical to eukaryotic TBPs) its overall structure is very similar to eukaryotic TBPs. The thermal unfolding transition temperature of this protein was measured by differential scanning calorimetry to be $101^{\circ} \mathrm{C}$, which is more than $40^{\circ} \mathrm{C}$ higher than that of yeast TBP. Preliminary titration calorimetry data show that the affinity of PwTBP for its DNA target, unlike its eukaryotic counterparts, is enhanced by increasing the temperature and salt concentration. The structure reveals possible explanations for this thermostability and these unusual DNA binding properties. The crystal structure of this hyperthermostable protein was compared to its mesophilic homologs and analyzed for differences in the native structure that may contribute to thermostability. Differences found were: (1) a disulfide bond not found in mesophilic counterparts; (2) an increased number of surface electrostatic interactions; (3) more compact protein packing. The presumed DNA binding surface of PwTBP, like its eukaryotic counterparts, is hydrophobic but the electrostatic profile surrounding the protein is relatively neutral compared to the asymmetric positive potential that surrounds eukaryotic TBPs. The total reliance on a hydrophobic interface with DNA may explain the enhanced affinity of $P w$ TBP for its DNA promoter at higher temperatures and increased salt concentration.

(C) 1996 Academic Press Limited

Keywords: Archaea; thermophile; structure; TBP; transcription

\section{Introduction}

The organism Pyrococcus woesei is a hyperthermophilic archaeal species found near deep-sea thermal vents and has an optimal growth temperature of $105^{\circ} \mathrm{C}$. Supporting the assertion that the archaeal cell and the eukaryotic nucleus share a common ancestor, homologs of the general eukaryotic transcription factors, TBP (Forterre, 1996; Marsh et al., 1994; Qureshi et al., 1995a; Rowlands et al., 1994), and transcription factor II B (TFIIB) (Ghosh et al., unpublished; Qureshi et al., 1995a,b), have recently been cloned from $P$. woesei and other archaeal species (TBP sequences aligned in

Abbreviations used: TBP, TATA-box binding protein; TFIIB, transcription factor II B; TFB, archaeal TFIIB-like factor; TFIIA, transcription factor II A; RMSD, root mean squared difference.
Figure 1). In a manner similar to eukaryotic Pol II transcription initiation, archaeal TBP binds upstream of transcription start sites at promoters containing A + T-rich sequences (Qureshi et al., 1995a; Rowlands et al., 1994). These DNA elements, called box A motifs, have a consensus sequence of ${ }_{\mathrm{T}}^{\mathrm{C}}$ TTA $\mathrm{A}$ ANN (Zillig et al., 1993; Palmer \& Daniels, 1995) that is similar to the eukaryotic TATA-box which has a consensus sequence of $\mathrm{TATA}_{\mathrm{T}}^{\mathrm{A}} \mathrm{A}_{\mathrm{T}}^{\mathrm{A}} \mathrm{N}$ (Bucher, 1990). The archaeal TFIIB-like factor, TFB, binds the archaeal TBP/DNA complex (Ghosh et al., unpublished results; Rowlands et al., 1994), and this TBP/TFB/DNA complex has been shown to be required for efficient and specific RNA transcription (Qureshi et al., 1995b), again similar to the homologous eukaryotic transcription system. In a further demonstration of the conservation between the archaeal and eukaryotic transcription systems, we have recently shown that archaeal TFB 
can cross kingdom lines by binding eukaryotic TBP/TATA box complexes (Ghosh et al., unpublished).

The crystal structures of the conserved C-terminal domain of two eukaryotic TBPs are known, one from the plant Arabidopsis thaliana (At TBP; Nikolov et al., 1992) and the other from the yeast Saccharomyces cerevisiae ( $S c \mathrm{TBP}$, TBPc denotes the conserved C-terminal 180 residues of TBP; Chasman et al., 1993; J. H. Geiger, unpublished crystal structure refined to $2.6 \AA$ ). The structure of the eukaryotic complex of TBP bound to DNA (J. Kim et al., 1993; Y. Kim et al., 1993) and the ternary complexes of TBP-DNA associated separately with TFIIB (Nikolov et al., 1995) and transcription factor II A (TFIIA) (Geiger et al., 1996; Tan et al., 1996) have also been determined by crystallography. Here we report the crystal structure of an archaeal TBP from $P$. woesei at $2.2 \AA$ resolution. The structure of this archaeal homolog of eukaryotic TBP offers insight into the evolution of the basal transcription machinery. While remarkably similar in its conformation to that of its eukaryotic counterparts, PwTBP shows a more compact folding and a different electrostatic charge potential distribution. These features help explain this molecule's remarkable thermostability and altered DNA binding properties.

\section{Results}

\section{Structure of PwTBP}

Soluble PwTBP (191 amino acids) was expressed in Escherichia coli, purified to homogeneity and crystallized by the hanging drop method using ammonium sulfate as a precipitant. An electrondensity map of PwTBP was synthesized at $3.1 \AA$ resolution with phases derived from isomorphous and anomalous differences of a mercurial derivative, and isomorphous differences from a crystal of selenomethionine substituted protein (Table 1). The current model is refined to an $R$-factor of 0.205 (free $R$-factor $=0.285)$, for data with $|F|>2 \sigma$ and Bragg spacings from 6.0 to $2.2 \AA$.

The conserved 180-residue core of TBP comprises a direct repeat sequence (Figure 1). The primary sequence of PwTBP extends in both the $\mathrm{N}$ and $\mathrm{C}$-terminal directions beyond this core. The region $\mathrm{N}$-terminal to the core, which is conserved neither in length nor composition in eukaryotic TBPs, consists of four residues in PwTBP. This extension is shorter than any reported for a eukaryotic TBP, which range in length from 18 residues in AtTBP to 158 residues in human TBP (HsTBP). The C terminus of PwTBP contains an "acidic tail" of seven residues which is conserved in the three

Table 1. Crystallography statistics

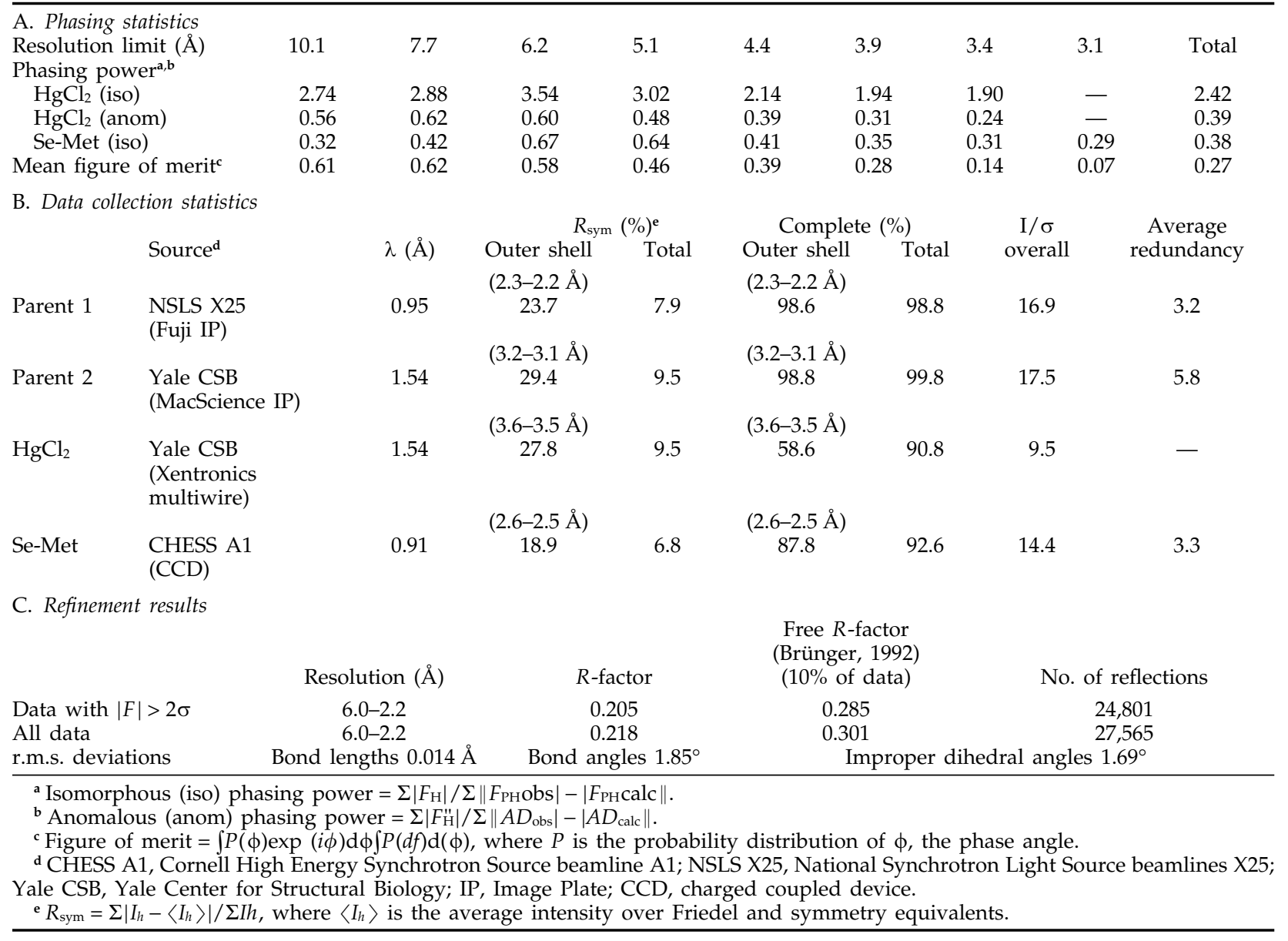




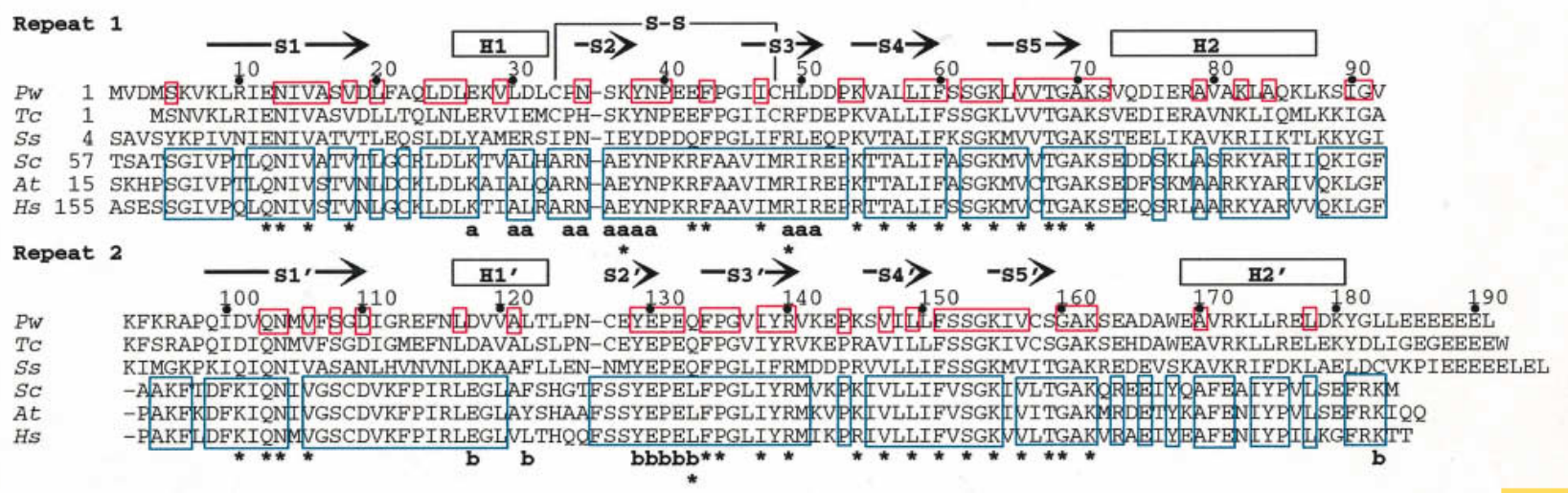

Figure 1. Sequences of the conserved $C$ termini of archaeal and eukaryotic TBPs aligned to maximize sequence identity and similarity (Genetic Computer Group, 1994). The three known TBP sequences from archaeal species are: Pw, Pyrococcus woesei; Tc, Thermococcus celer; Ss, Sulfolobus shibatea. (GenBank: Pwu10285; Tcu04932; Ssu23419) Representing the eukaryotic sequences are: Sc, Saccharomyces cerevisiae; At, Arabidopsis thaliana; Hs, Homo sapian. (SWISSPROT: Tf2d_yeast; Tf2d_arath; Tf2d_human) Numbering and secondary structure (S = beta sheet, $\mathrm{H}=$ alpha helix) labeled according to the PwTBP structure (Kabsch \& Sander, 1983). Disulfide shown between PwTBP residues 33 and 48 . Boxed in blue are residues conserved among eukaryotes and in red are residues conserved between PwTBP and ScTBPc. Residues involved in binding TFIIA, TFIIB, and DNA are labeled a, b, and *, respectively.

known archaeal TBPs but is not found in any eukaryotic TBP sequences. Sequence identity between PwTBP and the cores of all other eukaryotic TBPs ranges between $36 \%$ and $41 \%$ (Rowlands et al., 1994). Consistent with the high degree of sequence identity between archaeal and eukaryotic TBPs, the distribution of secondary structure and overall tertiary fold of PwTBP is essentially the same as those of the eukaryotic TBPs (Figure 2).

The structure of $\mathrm{TBPc}$ is composed of two very similar substructures which reflect a sequence repeat that is more pronounced in PwTBP $(40 \%$ sequence identity between repeats) than eukaryotes (28\% to $30 \%$ sequence identity between repeats). These substructures are approximately a

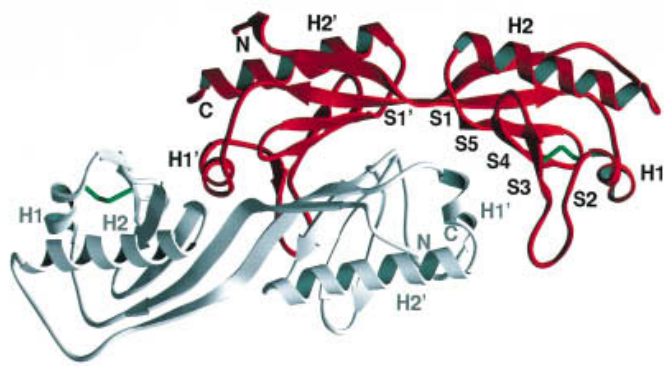

b

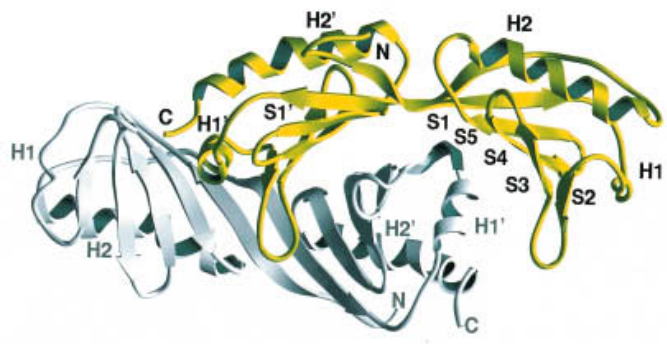

$\mathrm{C}$

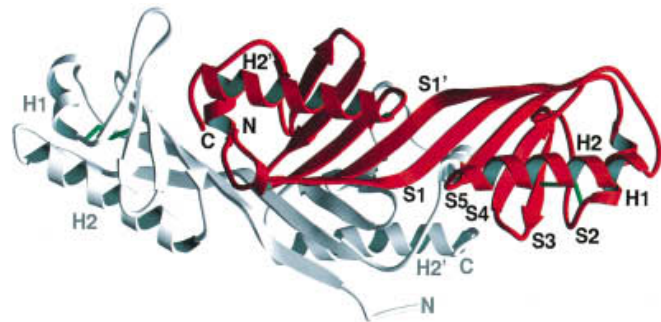

$\mathrm{d}$

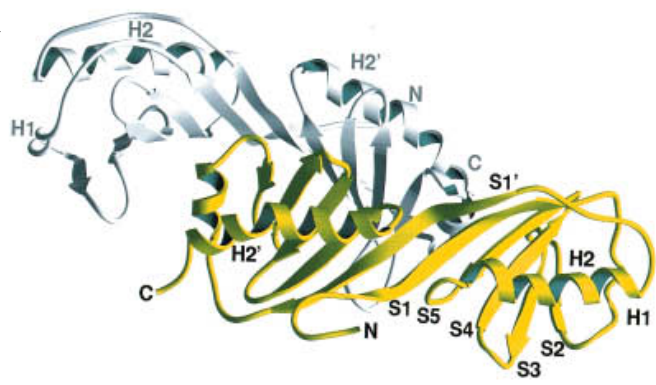

Figure 2. The crystal structures of archaeal and eukaryotic TBPs emphasizing secondary structure and rendered by the program Ribbons (Carson, 1991). a, Ribbons drawing of PwTBP showing both molecules of the asymmetric unit. The disulfide bond between Cys33 of alpha helix H1 and Cys48 of beta strand S3 is green. b, Ribbons drawing of ScTBPc (J. H. Geiger, crystal structure refined at $2.6 \AA$ ) showing both molecules of the asymmetric unit with the yellow representation oriented as the red molecule of a. The dimer arrangement of ScTBPc is similar to that observed in the other eukaryotic TBP crystal structure from the species A. thalinia (Nikolov et al., 1992). c and d, Same as a and b, respectively, with view rotated by $90^{\circ}$ along the horizontal axis in the plane of the paper showing the top of the molecule highlighted in $a$ and $b$. 


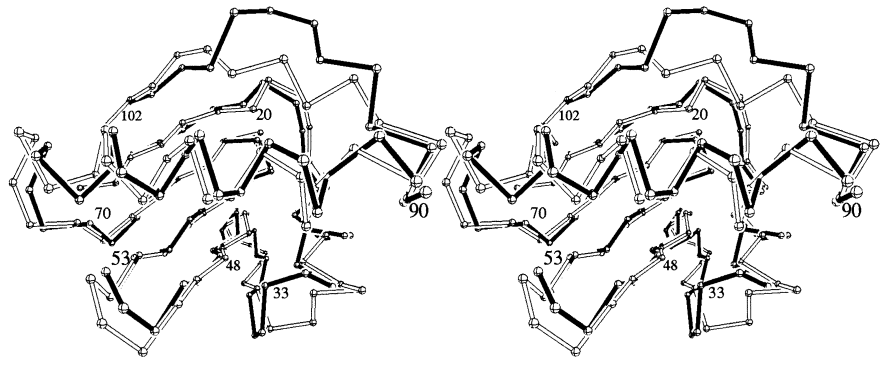

a
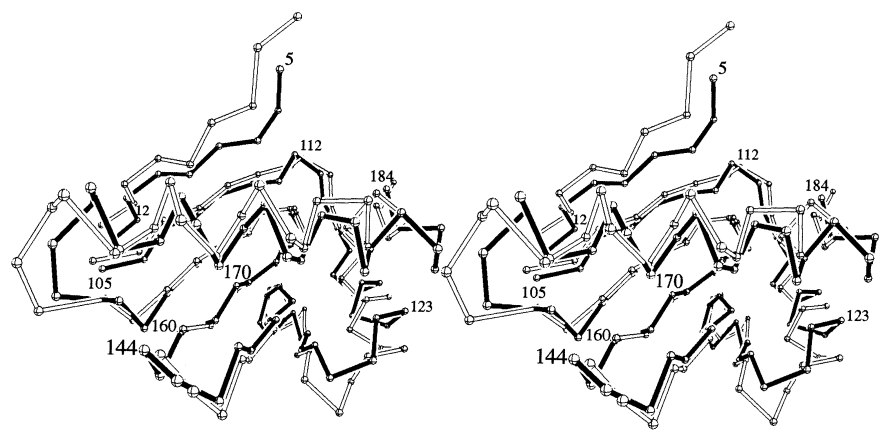

b
Figure 3. $\mathrm{C}^{\alpha}$ carbon traces of PwTBP com ared to that of ScTBPc. a, Superposition of N-terminal substructure of PwTBP (filled black bonds) and ScTBPc (outlined bonds) numbered according to PwTBP sequence and oriented roughly like the $\mathrm{N}$-terminal substructure in the right-hand side of Figure 2a. Pro53 and the corresponding ScTBPc residue are in the cis configuration. Residues 33 and 48 are connected by a disulfide bond in the PwTBP structure. Extended loop in PwTBP structure between residues 90 and 102 is the result of a sequence insertion in this region (Figure 1). b, C-terminal substructure and a short sequence of the $\mathrm{N}$ terminus of PwTBP (filled black bonds) superimposed upon $S c \mathrm{TBPC}$ (outlined bonds) oriented as in a. Numbered according to PwTBP sequence. Pro144 and the corresponding $S c \mathrm{TBP}$ residue are in the cis configuration. dyad symmetric and deviate from one another with a root mean squared difference (RMSD) of $1.8 \AA$ for corresponding $\mathrm{C}^{\alpha}$ atoms. If the $\mathrm{N}$-terminal substructure of PwTBP is superimposed on its counterparts from ScTBPc and AtTBP, the RMSDs for corresponding $C^{\alpha}$ atoms are $1.9 \AA$ and $2.0 \AA$, respectively (Figure $3 a$ ). The same alignment of the C-terminal substructures results in a RMSD of $2.5 \AA$ between PwTBP and ScTBPc and $2.6 \AA$ between PwTBP and AtTBP (Figure $3 \mathrm{~b}$ ). The sequences of ScTBPc and AtTBP are $81 \%$ identical, which is reflected in a higher structural similarity between them than between either and PwTBP. A compari- son of the two substructures of the eukaryotic TBPs results in $1.0 \AA$ and $1.5 \AA$ RMSD between corresponding $C^{\alpha}$ atoms for the $\mathrm{N}$-terminal and $C$-terminal repeats, respectively.

Proline residues 53 and 144 of PwTBP are in the cis configuration as are their eukaryotic counterparts. Cysteine 33 and cysteine 48 are unique to the two sequenced hyperthermophilic archaeal TBPs, P. woesei and T. celer (Figure 1), and form a disulfide bond (Figures 2 and 4). Electron density in simulated annealing omit maps (Brünger, 1993), in which both cysteine residues and an area encompassing a radius of $8 \AA$ surrounding them was
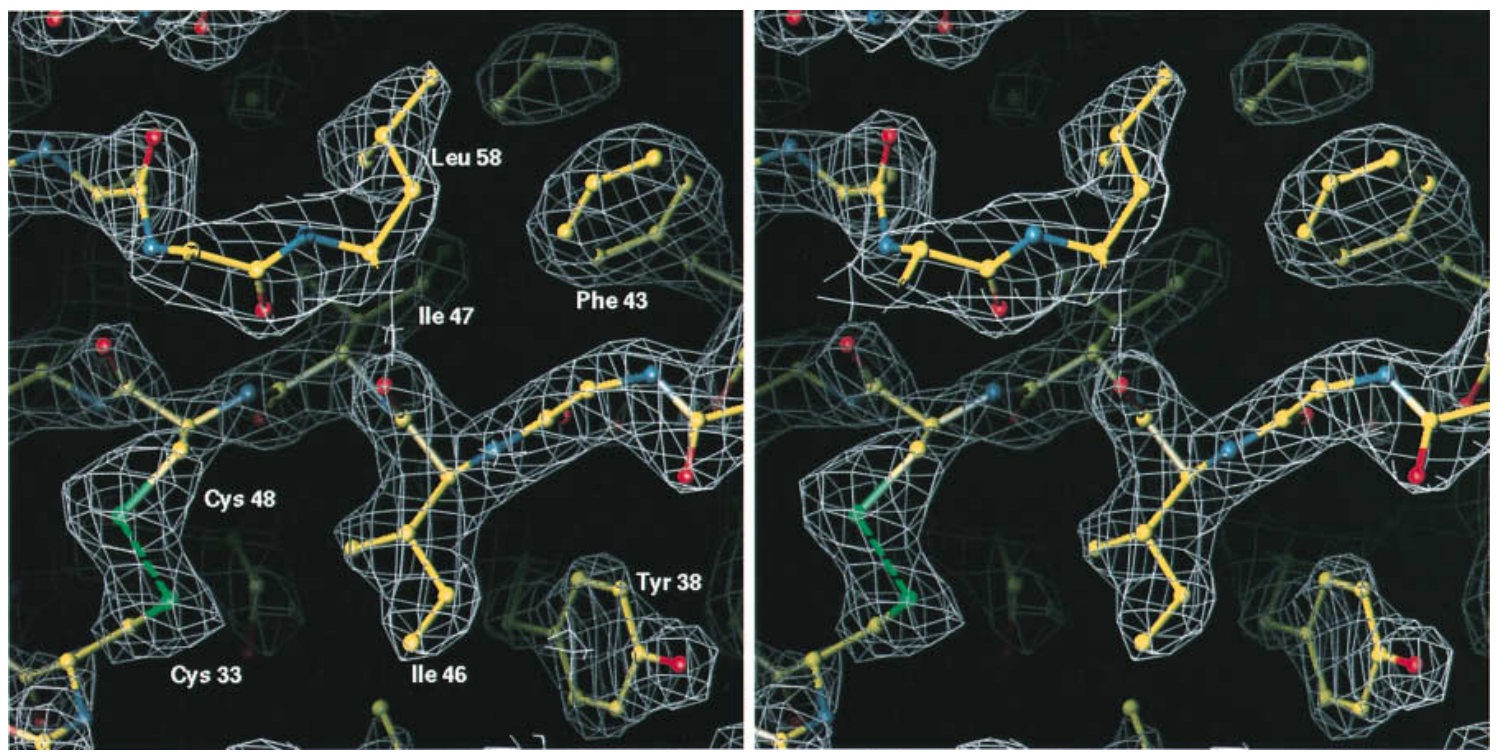

Figure 4. Stereo pair showing $2 F_{\mathrm{o}}-F_{\mathrm{c}}$ electron-density map contoured at $2.0 \sigma$. The disulfide bond between Cys33 and Cys48 is shown. 


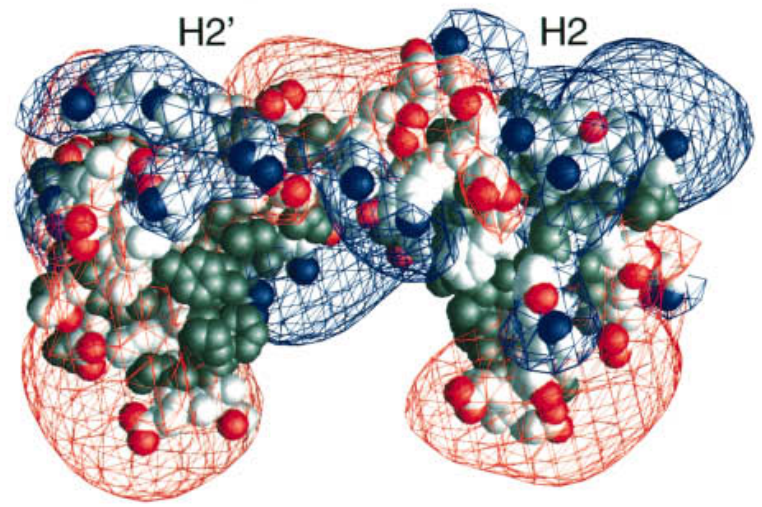

a

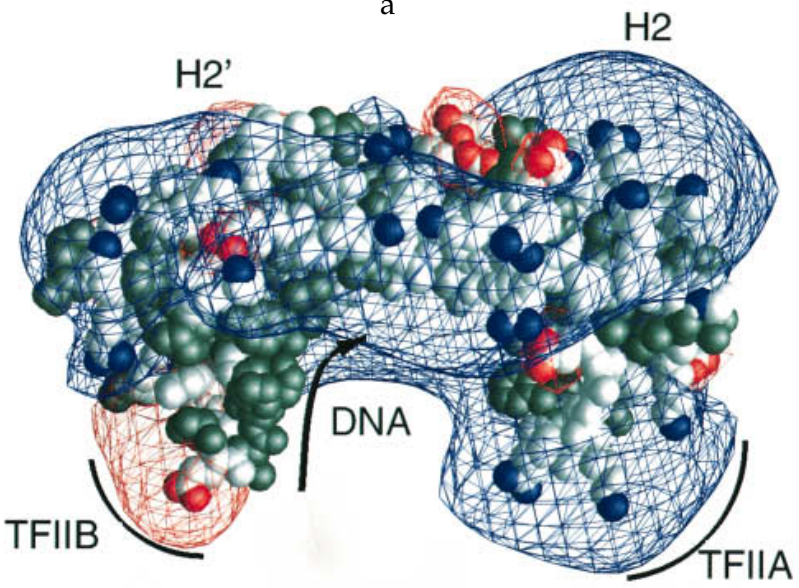

$\mathrm{b}$

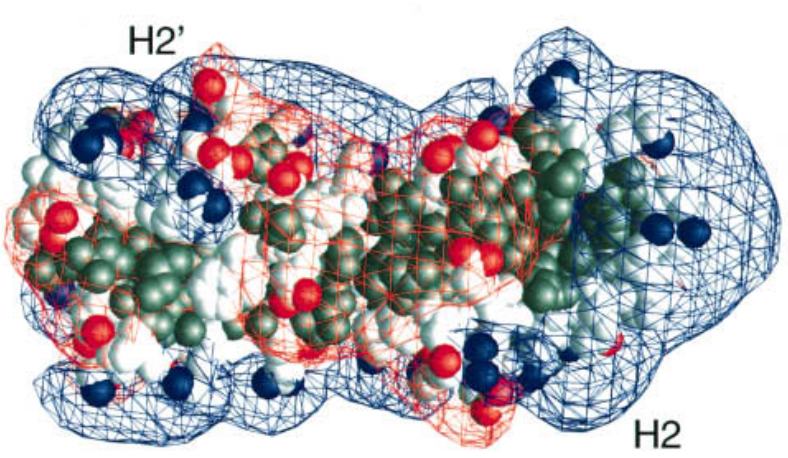

C

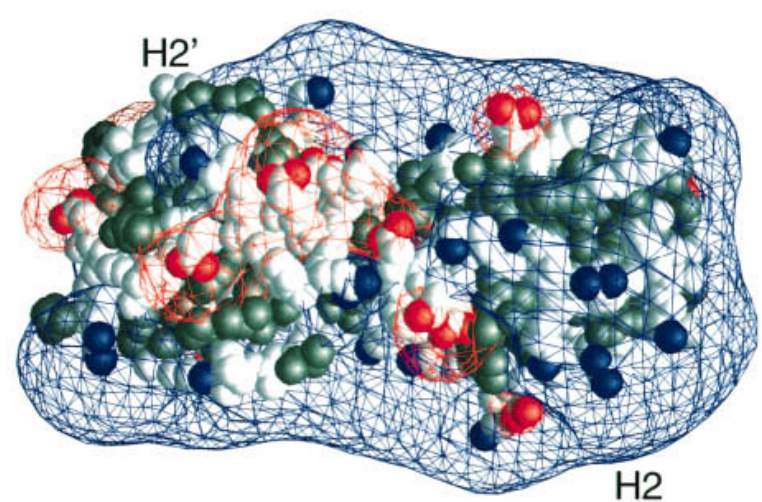

$\mathrm{d}$

Figure 5. Electrostatic potential surrounding PwTBP (a) and ScTBPc (b) calculated in $100 \mathrm{mM}$ salt and rendered with the program GRASP (Nicholls et al., 1993). Orientation of the protein is the same as the red molecule of Figure 2a. Positive potentials are blue and negative potentials are red with both contoured at a magnitude of $1 \mathrm{kT}$. Charged nitrogen atoms are shown in blue, charged oxygen atoms red, and hydrophobic residues green. Electrostatic potential of PwTBP (c) and ScTBPc (d) labeled the same as above and oriented as the red molecule in Figure 2c.

omitted, confirmed a disulfide bond between them. Based on this density they were refined as cystine. Proline 232 (yeast numbering), which is highly conserved in eukaryotic TBPs and is responsible for a kink in the H2' helix, is not present in the PwTBP sequence. This allows the H2' helix of PwTBP to remain linear, as is the $\mathrm{H} 2$ helix in all TBP structures, archaeal and eukaryotic.

The electrostatic potential surrounding PwTBP is dramatically different than that of its eukaryotic counterparts (Figure 5). This is due to more acidic residues on the surface of the PwTBP molecule that result in more ion-pairs (Table 2) and a corresponding neutralization of the positive potential seen in the eukaryotic structures. The possible implications of this on DNA affinity is discussed below.

\section{Homodimer formation}

As seen for the eukaryotic TBPs, HsTBP, AtTBP, and ScTBPc (Coleman et al., 1995; Nikolov \& Burley, 1994), the archaeal TBP is a dimer in solution as determined by gel filtration (data not shown). Consistent with the dimer formation seen in solution, the crystal structures of all TBPs reveal a dimer in the asymmetric unit, with the monomers related by a non-crystallographic dyad (Figure 2). In all crystal structures (eukaryotic and archaeal) the C-terminal repeats make up most of the dimer interface and mask the hydrophobic DNA-binding surface of each molecule. As shown in Figure 2, the two eukaryotic TBPs dimerize in a similar manner with a solvent-excluded interface for each monomer of $1600 \AA^{2}$. The interface between the two monomers in the asymmetric unit of $P w$ TBP also buries $1600 \AA^{2}$ of solvent accessible surface area (Table 2), but the nature of the interface is distinctly different (Figure 2), and thus a specific dimer arrangement is not evolutionarily conserved.

\section{Hyperthermostability}

To test the thermostability of PwTBP, the melting temperature was determined by differential scanning calorimetry (Figure 6). The midpoint of the thermal denaturation was $101^{\circ} \mathrm{C}$ in $50 \mathrm{mM}$ 
Table 2. Structure statistics ${ }^{\mathrm{a}}$

\begin{tabular}{|c|c|c|c|}
\hline & $P w$ TBP & Sc TBPc & AtTBP \\
\hline Total number of atoms & 1403 & 1415 & 1421 \\
\hline Hydrogen bonds (no.) ${ }^{\mathbf{b}}$ & $278 / 264$ & $265 / 272$ & $273 / 276$ \\
\hline $\begin{array}{l}\text { Ion pairs (no.) } \\
\text { Monomers } \\
\text { Dimer interface }\end{array}$ & $\begin{array}{r}7 / 8 \\
2\end{array}$ & $2 / 4$ & $\begin{array}{r}5 / 4 \\
0\end{array}$ \\
\hline $\begin{array}{l}\text { Solvent-accessible surface ar } \\
\text { Monomers } \\
\text { Buried in dimer interface }\end{array}$ & $\begin{array}{c}9800 / 9600 \\
1600\end{array}$ & $\begin{array}{c}10,100 / 10,400 \\
1500\end{array}$ & $\begin{array}{c}9800 / 10,000 \\
1700\end{array}$ \\
\hline $\begin{array}{l}\text { Solvent-accessible surface ar } \\
\text { Non-polar } \\
\text { Polar } \\
\text { Charged } \\
\text { Of charged \% positive }\end{array}$ & $\begin{array}{l}\text { on }(\%) \\
56 / 55 \\
18 / 19 \\
26 / 26 \\
(55 / 55)\end{array}$ & $\begin{array}{l}60 / 61 \\
17 / 15 \\
23 / 24 \\
(72 / 73)\end{array}$ & $\begin{array}{c}60 / 59 \\
17 / 16 \\
23 / 25 \\
(69 / 70)\end{array}$ \\
\hline Atoms buried $(\%)^{\mathbf{e}}$ & $46 / 45$ & $45 / 43$ & $46 / 46$ \\
\hline Protein density ${ }^{f}$ & $0.818 / 0.815$ & $0.796 / 0.798$ & $0.793 / 0.796$ \\
\hline Void volume $\left(\AA^{3}\right)^{\mathrm{g}}$ & $4100 / 4200$ & $4800 / 4700$ & $4900 / 4800$ \\
\hline \multicolumn{4}{|c|}{$\begin{array}{l}\text { a Calculations include both molecules in the asymmetric unit (A/B) and residues } 5 \text { to } 184 \text { of the } \\
\text { PwTBP structure, } 19 \text { to } 198 \text { of the AtTBP structure (Nikolov et al., 1992), } 61 \text { to } 240 \text { of the ScTBPc } \\
\text { structure (J. H. Geiger, crystal structure refined at } 2.6 \AA \text { ). } \\
\text { b Hydrogen bonds were defined by the method of Kabsch \& Sander (1983). } \\
\text { ' } \text { Ion-pairs were defined as two ionizable groups } \leqslant 4 \AA \text { apart (Barlow \& Thornton, 1983). } \\
\text { d The algorithm of Lee \& Richards (1971) using a probe radius of } 1.4 \AA \text {. } \\
\text { e Atoms with no solvent accessible surface. } \\
\text { ' Molecular volumes using the program PQMS (Connolly, 1985), and the atomic radii reported } \\
\text { by Rashin et al. (1986). Data for all structures compared were collected on frozen crystals. van der } \\
\text { Waals volume, volume calculated with zero } \AA \text { radius probe. Solvent-excluded volume, volume } \\
\text { calculated with } 1.4 \AA \text { radius probe. Protein density, van der Waals volume/solvent-excluded } \\
\text { volume. } \\
\text { g Void volume = solvent-excluded volume - van der Waals volume. }\end{array}$} \\
\hline
\end{tabular}

potassium phosphate $(\mathrm{pH}$ 7.0). Under reducing conditions the transition decreased to $97^{\circ} \mathrm{C}$ and in high salt ( $800 \mathrm{mM}$ potassium phosphate) the transition increased to $109^{\circ} \mathrm{C}$. Thus, pure bacterially expressed PwTBP is, indeed, extremely thermostable indicating that neither endogenous cellular factors nor in vivo modifications are needed for this property.

\section{PwTBP-DNA interaction}

A thorough analysis of the salt and temperature dependence of PwTBP-DNA interactions is presently under way. Preliminary results indicate a salt and temperature dependence for the binding of PwTBP to its DNA target that is distinctly different from that observed for its eukaryotic counterparts. At room temperature gel mobility shift assays show weak affinity of PwTBP for the elongation factor $1 \alpha$ promoter, AAGCTTTAAAAAGTAA (box A sequence underlined; Rowlands et al., 1994). At approximately the intracellular salt, concentration found in $P$. woesei, $800 \mathrm{mM}$ potassium phosphate (Scholz et al., 1992), titration calorimetry experiments show that PwTBP binds specifically to the same box A sequence with a dissociation constant $\left(K_{\mathrm{d}}\right)$ of $13 \mu \mathrm{M}$ at $25^{\circ} \mathrm{C}$ (data not shown). Increasing the salt concentration to $1.3 \mathrm{M}$ potassium phosphate enhances affinity 24 times while decreasing it to $50 \mathrm{mM}$ potassium phosphate abolishes any detectable enthalpy of binding. Earlier gel mobility shift assays by Rowlands et al. (1994), indicated enhanced affinity at 55 to $60^{\circ} \mathrm{C}$, and titration calorimetry experiments corroborate this by showing that affinity is enhanced 30 times when the temperature is raised to $45^{\circ} \mathrm{C}$. If both the salt concentration and temperature are elevated to $1.3 \mathrm{M}$ potassium phosphate and $45^{\circ} \mathrm{C}$, then the affinity is enhanced 370 times to give a $K_{d}$ of $35 \mathrm{nM}$, as shown by titration calorimetry. By contrast, the affinity of ScTBP for the TATA-box $\left(K_{\mathrm{d}}=2.4 \mathrm{nM}\right.$; Hahn et al., 1989), is diminished 300 times when the salt concentration is increased from $50 \mathrm{mM}$ to $300 \mathrm{mM}$ potassium chloride and also decreases at temperatures exceeding $30^{\circ} \mathrm{C}$ (Petri et al., 1995). Although the temperatures for these in vitro studies are well below the optimal growth temperature of $P$. woesei $\left(105^{\circ} \mathrm{C}\right)$, it is clear that elevated temperature and increased salt concentration enhance the stability of the archaeal complex at levels which destabilize the eukaryotic interaction.

\section{Interface with general and specific transcription factors}

The crystal structure of AtTBP complexed with Homo sapiens TFIIB and DNA demonstrated that TFIIB interacts with the C-terminal "stirrup" of AtTBP (Nikolov et al., 1995). Of the eight residues contacted by TFIIB, all but two are conserved or are similar in PwTBP, and there are no charge reversals (Figure 1). Not surprisingly the TFIIB homolog in 


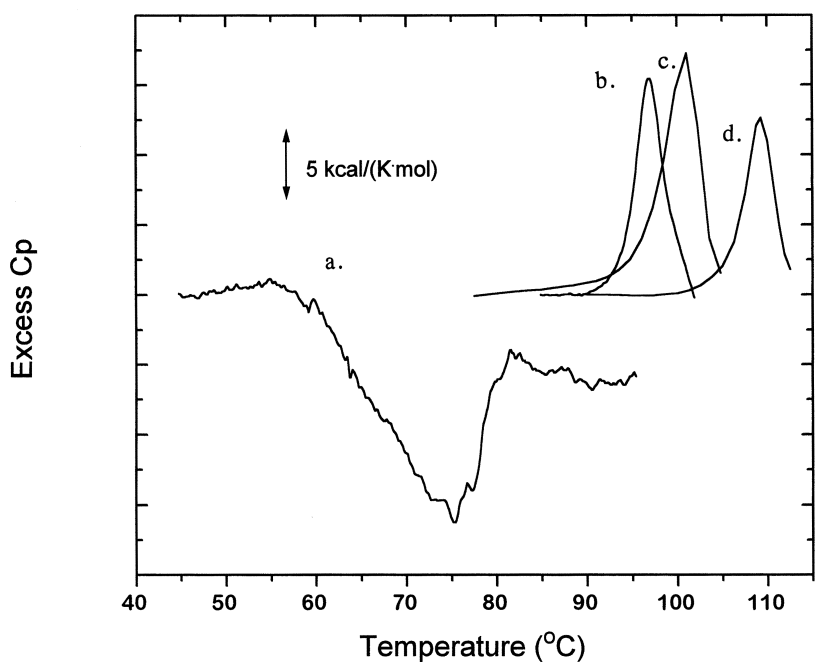

Figure 6. Thermal transitions of $P w \mathrm{TBP}$ and $\mathrm{ScTBPC}$ measured by differential scanning calorimetry. a, Exothermic denaturation/aggregation of ScTBPc $(50 \mathrm{mM}$ potassium phosphate $\mathrm{pH} 7.0,10 \%$ glycerol) with transition and presumed unfolding occurring about $60^{\circ} \mathrm{C}$. $\mathrm{b}$ to $\mathrm{d}$, Unfolding transition of PwTBP in (b) reducing conditions (2 mM dithiothreitol (DTT), $50 \mathrm{mM}$ potassium phosphate, $\mathrm{pH} 7.0$ ), (c) oxidizing conditions $(50 \mathrm{mM}$ potassium phosphate, $\mathrm{pH}$ 7.0) which is identical with $10 \%$ glycerol added; and (d) high salt and oxidizing conditions ( $800 \mathrm{mM}$ potassium phosphate, $\mathrm{pH} 7.0$ ).

archaea, TFB, forms strong interactions with both archaeal and eukaryotic TBP/DNA complexes (Rowlands et al., 1994; Ghosh et al., unpublished). This is consistent with the fact that well ordered crystals of the PwTFB/PwTBP/A-box have been reported (Kosa et al., 1996).

Yeast TFIIA (ScTFIIA) is a negatively charged molecule that interacts with four basic residues along the N-terminal "stirrup" of ScTBPc (Geiger et al., 1996; Tan et al., 1996). None of these basic residues in ScTBPc are conserved in PwTBP, and two are of opposite charge. In fact, most of the TBP residues that contact TFIIA in the $S c$ TBPc/ScTFIIA/TATA complex are not conserved (Figure 1). A negative potential surrounds the N-terminal stirrup of PwTBP (Figure 5) and this negative potential would repel the negative charge of a yeast like TFIIA molecule. Additionally, the disulfide bond in PwTBP alters the conformation of the S2 strand of PwTBP relative to that of the eukaryotic TBPs. This S2 strand forms the predominant interacting surface of ScTBPc with ScTFIIA. An archaeal TFIIA homolog has not yet been identified, and if one were to exist, its binding surface to TBP would have to be significantly different.

Basic residues project from the surface of the $\mathrm{H} 2$ helix of PwTBP in a manner similar to that found in eukaryotic TBPs (Figure $5 c$ and d). This region, in eukaryotic TBPs, has been implicated in binding the activation domains of eukaryotic transcription factors such as p53 and E1A (Lee et al., 1991; Liu et al., 1993). Although endogenous activators have not been found in Archaea, these eukaryotic activators have been shown to bind PwTBP (Rowlands et al., 1994). Since PwTBP contains a basic region on the $\mathrm{H} 2$ helix similar to that of eukaryotic TBPs, it is possible that PwTBP's interactions with some eukaryotic activators are also similar to that of eukaryotic TBPs.

\section{Discussion}

\section{Hyperthermostability}

Hyperthermophilic organisms are those which grow optimally at temperatures exceeding $90^{\circ} \mathrm{C}$ (Adams, 1993). Based on phylogenetic studies, most hyperthermophilic genera have been classified as Archaea, while two are Bacteria (Woese et al., 1990). $P$. woesei is a hyperthermophilic archaeal species, and as expected, the TBP molecule from this organism is stable at the high temperatures. PwTBP has an unfolding transition of $101^{\circ} \mathrm{C}$ which is $40^{\circ} \mathrm{C}$ higher than ScTBPc under comparable conditions (Figure 6). While the free energy level of both the unfolded and native forms contribute to the thermostability of a protein (Dill \& Shortle, 1991), this study can only address contributions to stability from the native state since the denaturation is irreversible.

In the crystallographic study of the hyperthermophilic enzyme aldehyde ferredoxin oxidoreductase, the authors conclude that an unusually high fraction of buried atoms (55\%) and a corresponding reduced solvent accessible surface area correlates with the thermostability of that molecule (Chan et al., 1995). The amount of solvent accessible surface area of PwTBP, although less than its eukaryotic homologs is still $7 \%$ greater than the average protein of its size (Miller et al., 1987). In addition, PwTBP does not bury an unusual large fraction of its atoms and is identical in this respect to the mesophilic TBPs (Table 2).

One unusual feature of the PwTBP structure that could contribute to its thermostability, is its single disulfide bond. Typical of intracellular proteins, disulfide bonds have not been found in the mesophilic TBPs. However, when the unfolding transition temperature of PwTBP under oxidizing conditions was compared with the transition in a reducing environment (Figure 6), only a modest decrease of $4^{\circ} \mathrm{C}$ in the transition temperature was observed under reducing conditions.

Four recent studies comparing the crystal structures of hyperthermophilic proteins to those of their mesophilic homologs revealed an increase in the number of ion-pairs in the hyperthermophilic versions (Day et al., 1992; Hennig et al., 1995; Korndörfer et al., 1995; Yip et al., 1995). The number of ion-pairs, defined as two ionizable groups $\leqslant 4 \AA$ apart (Barlow \& Thornton, 1983), were calculated for the known TBP structures. PwTBP contains eight ion-pairs on its surface and in comparison, the eukaryotic TBPs have four and five surface ion-pairs (Table 2). Although PwTBP contains more surface ion pairs than the mesophilic TBPs, the 


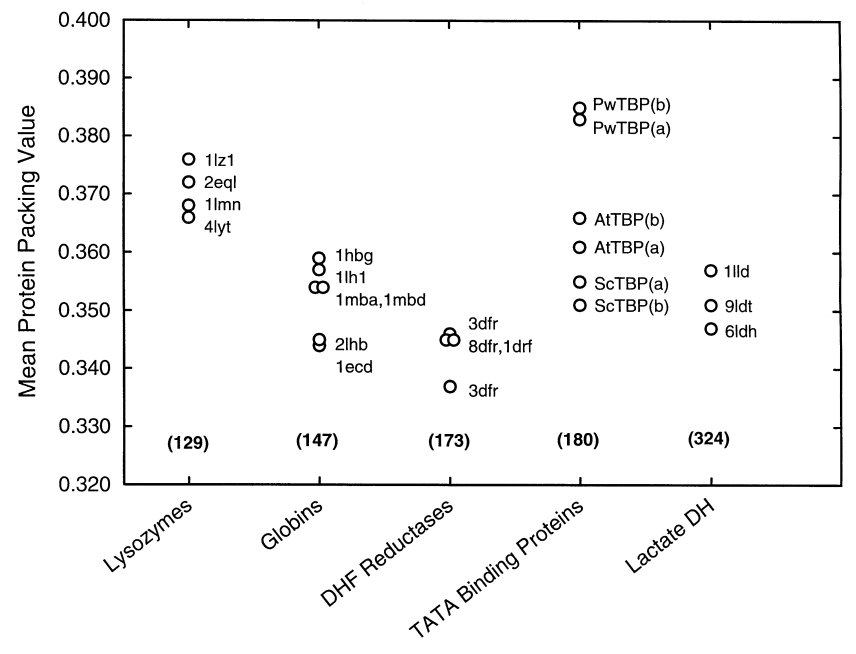

Figure 7. Atomic packing in homologous protein structures. The mean packing value for each protein without prosthetic groups was calculated from analysis of occluded surface as described in the text. Data points are labeled with the respective PDB identifier codes. The homolog families shown for comparison are all groups of high resolution crystal structures $(<2.2 \AA)$ available in the PDB that have high sequence divergence among the members. The numbers in parentheses are the average numbers of amino acid residues per protein in the respective groups. Monomers of the dimeric TATA binding proteins found in the asymmetric unit are labeled $a$ and $b$.

observation of increased thermostability at higher salt concentrations for PwTBP (Figure 6) argues against electrostatic interactions as the predominant stabilizing force, since the stabilizing effect of a surface ion-pair is not likely to be enhanced by raising the ionic strength of the buffer.

Richards observed that the interiors of proteins are tightly packed with densities similar to those of crystals of small organic molecules (Richards, 1974). Studies of the density of protein interiors have implicated "packing efficiency" as a factor in protein stability (for review, see Richards \& Lim, 1994). A mean protein packing value was calculated for the TBP structures and the packing value of $P w$ TBP is $6 \%$ greater than that of $A t \mathrm{TBP}$, the closest mesophilic TBP (Figure 7). A survey of packing values is shown for several families of homologous proteins in Figure 7. PwTBP is clearly the most efficiently packed; but more important, its packing value deviates from that of its homologs by a substantial margin, whereas the packing values of other families are more tightly clustered. A complete analysis of the packing efficiency comparing hyperthermophiles and their mesophilic counterparts is currently under way. The increased packing density of PwTBP is due mostly to the contraction of several segments toward the protein core as demonstrated in the difference distance matrix (Figure 8). The contraction of PwTBP has eliminated about $12 \%$ of the void volume found within the solvent-excluded volume of the mesophilic proteins (Table 2). The elimination of this void space and consequent increase in packing efficiencies could contribute to the thermostability of PwTBP by increasing the associated favorable van der Waals interactions (Richards \& Lim, 1994).

Rather than a single specific structural attribute, a combination of chemical characteristics known to stabilize mesophilic proteins may work together to increase the thermostability of PwTBP. Crystal structures of proteins from hyperthermophilic organisms, including PwTBP described here, highlight several of these chemical characteristics for increasing protein thermostability: (1) disulfide bonds; (2) more ion-pair interactions; (3) increased buried surface area; (4) more compact packing.

\section{PwTBP-DNA interaction}

The structure of PwTBP gives a plausible explanation for the different effects of salt and temperature on the affinity of eukaryotic and archaeal TBPs for their respective DNA targets. The majority of contacts between eukaryotic TBPs and DNA are hydrophobic in nature (J. L. Kim et al., 1993; Y. Kim et al., 1993). Unlike ionic and polar contacts, hydrophobic interactions are not diminished by high salt and elevated temperature; in fact, they are often strengthened under these conditions. In PwTBP, 21 of the 25 residues which are involved in hydrophobic contacts between eukaryotic TBPs and the TATA-box are preserved, and modeling suggests that those which differ would not be disruptive to the PwTBP/DNA complex. Moreover, these ionic/polar contacts between eukaryotic TBP and the DNA backbone are replaced by residues that can only form van der Waals contacts with the sugars. Since the hydrophobic effect is predominantly entropic, an enhanced affinity of TBP for DNA might be expected at higher temperatures which is indeed the case for PwTBP. That eukaryotic TBP's affinity for DNA decreases at elevated salt concentrations may be explained by the fact that in the case of the eukaryotic complex the hydrophobic interactions are supplemented by polar contacts (J. L. Kim et al., 1993; Y. Kim et al., 1993) and the protein's positive electrostatic potential. In addition to providing an attractive binding force, the positive potential flanks the phosphates of the bound TATA-box helping to splay open the minor groove of the DNA and, thereby bend the DNA target (J. L. Kim et al., 1993; Y. Kim et al., 1993). Thus, high salt concentrations would be expected to diminish these electrostatic contributions to the stability of eukaryotic TBP/ DNA complexes. In PwTBP, however, the large number of surface acidic side-chains that form the frequent ion pairs noted above in connection with thermal stability, create a nearly electrostatically neutral surface (Figure 5). Thus, the PwTBP/DNA complex would not be stabilized by the electrostatic interactions to the extent seen in the eukaryotic TBP/DNA complexes, and increasing the salt concentration would not be expected to reduce PwTBP's affinity for DNA as it does to ScTBP's. 


\section{Protein evolution}

In many ways, the hyperthermophilic genera of the Bacteria and Archaea appear to be the most ancient of their respective kingdoms (Woese et al., 1990). It has been proposed that the common ancestor of all existent life was a hyperthermophile, and that relatively modern mesophilic biology is adapted from an earlier hot environment (Woese, 1987). This assertion has been debated by those who point to the adaptive stress imposed by high temperature on DNA repair (for a review, see Forterre, 1996).

Regardless of the sign of the presumed thermal gradients in evolution, the contrast of PwTBP and its eukaryotic counterparts provides a window into the adaptation of a DNA binding protein to a range of temperatures. Stability of the PwTBP/ TATA-complex at high temperature and high salt concentrations exploits the thermal and salt dependence of the hydrophobic effect; i.e. stability of the hydrophobic interaction is

a $<=-6.0 \bigcirc-4.8 \bigcirc-3.6 \bigcirc-2.4-1.2 \quad 0.0 \quad 1.2 \quad 2.4 \div 3.6 \bigcirc 4.8 \bigcirc 6.0>=$

PW TBP

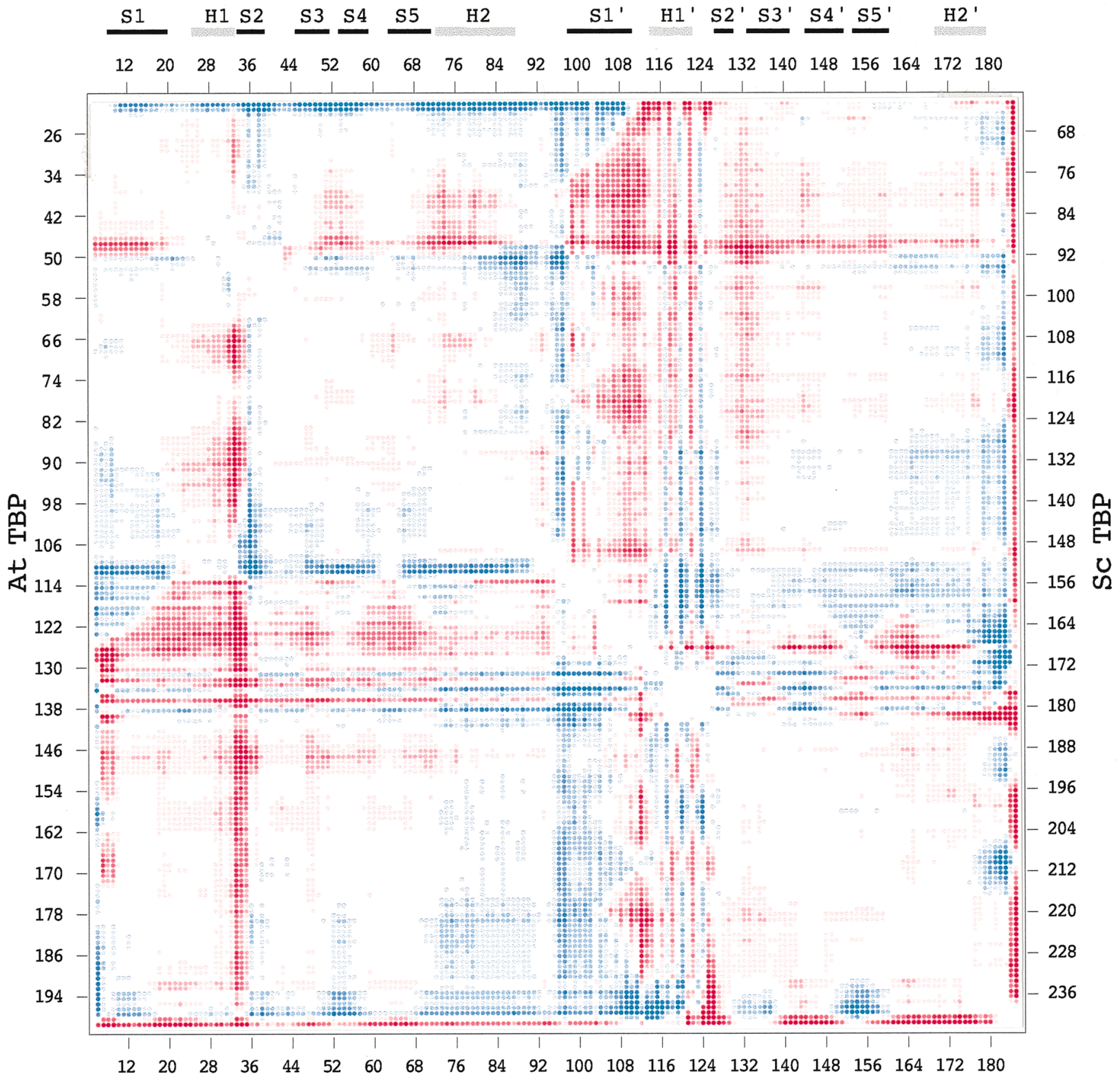

PW TBP

Figure 8a legend on page 1081 
b
$<=-6.0$
$-4.8$
$\begin{array}{lll}-3.6 & -2.4 & -1.2\end{array}$
0.0

\section{PW TBP-A}

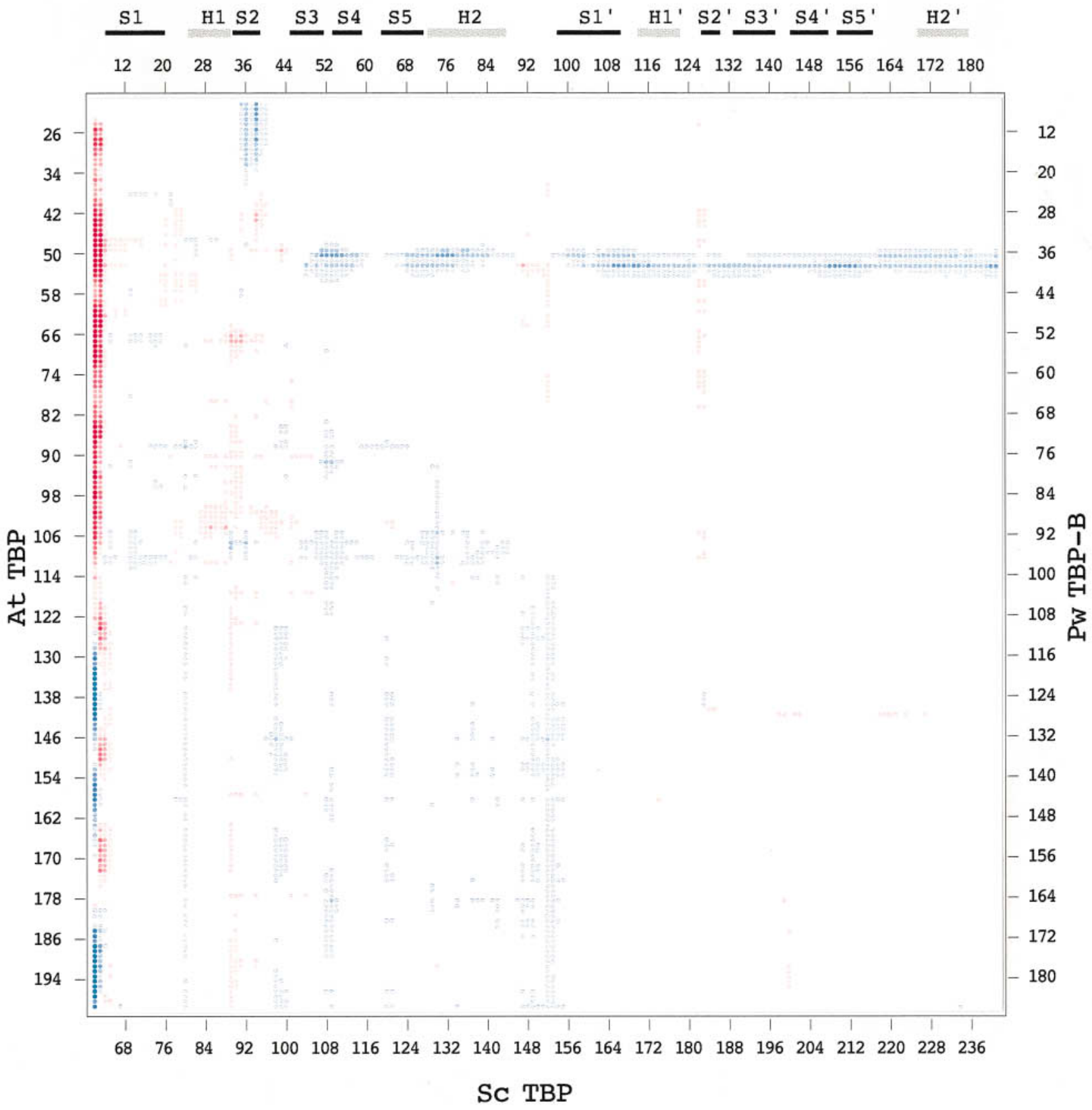

Figure 8. Difference distance matrix of $C^{\alpha}$ atoms. a, Red indicates that the respective intramolecular $C^{\alpha}-C^{\alpha}$ distances of PwTBP are contracted compared to either ScTBPc (above and right of diagonal) or AtTBP (below and left of diagonal). Blue indicates a corresponding expansion. The relative contraction or expansion is indicated by the color scale at the top of the Figure. Relative displacements of several segments are evident in the Figure. For example the vertical red streak between $\mathrm{H} 1$ and S2 shows that the disulfide bond in PwTBP brings Cys33 and the H1 helix closer to most other $\mathrm{C}^{\alpha}$ positions when compared to the eukaryotic TBPs. In contrast, the residue insertion between $\mathrm{H} 2$ and S1'(see Figure 4a) has resulted in an outward displacement of this loop relative to the core of the first domain as seen by the vertical blue streak in this region. $b$, "Control" comparison of the two PwTBP molecules in the asymmetric unit (above and right of diagonal) and between the two eukaryotic structures (below and left of diagonal). Major differences between the two PwTBP molecules in the asymmetric unit representations can be seen at Ser36 and Tyr38 which are in the N-terminal stirrup loop. The only significant differences in $\mathrm{C}^{\alpha}$ positions between $S c \mathrm{TBPC}$ and $A t \mathrm{TBP}$ are in the $\mathrm{N}$-terminal two residues which probably precede the functional structures. 
enhanced by high temperature and high salt. However, the PwTBP described here is only the first DNA-binding regulatory protein in hyperthermophiles to be analyzed structurally. The structure/function relationships of many more cases must be analyzed before physical chemical correlates can be confidently extracted.

\section{Materials and Methods}

\section{Protein expression and purification}

Full length PwTBP was expressed using a T7 polymerase-based expression system (Novagen) in the E. coli strain BL21(DE3). Protein was purified by heating the cell extract to $80^{\circ} \mathrm{C}$ for 15 minutes, which precipitated the majority of the E. coli proteins, leaving the PwTBP in the soluble fraction. The supernatant was then fractionated on hydroxyapatite (BioRad) followed by Mono-Q (Pharmacia). PwTBP eluted from the hydroxyapatite column at $200 \mathrm{mM}$ potassium phosphate $(\mathrm{pH} 7.0)$ using a $100 \mathrm{mM}$ to $300 \mathrm{mM}$ gradient, and eluted as a homogeneous protein (as determined by sodium dodecyl sulfate/polyacrylamide gel electrophoresis and Coomassie blue stain) from the Mono-Q column at $250 \mathrm{mM}$ potassium chloride and $20 \mathrm{mM}$ Tris $(\mathrm{pH} 7.5)$ using a $100 \mathrm{mM}$ to $400 \mathrm{mM}$ gradient. The protein molecular mass was determined to be $21,320( \pm 10)$ daltons by electrospray mass spectroscopy (Yale mass spectrometry facility), consistent with the calculated 21,311 daltons deduced from the DNA sequence. Protein concentration was determined spectroscopically using the calculated value for $\epsilon_{280}$ of $11,050 \mathrm{M}^{-1} \mathrm{~cm}^{-1}$ based on the extinction coefficients of the chromophores present in the protein sequence in $6 \mathrm{M}$ guanidine (Pace et al., 1995). Final recovery of pure protein was $10 \mathrm{mg}$ per liter of E. coli cell growth.

\section{Crystallization and structure determination}

Hexagonal crystals $\left(0.2 \mathrm{~mm} \times 0.2 \mathrm{~mm} \times 0.4 \mathrm{~mm}, P 6_{1}\right.$, $a=b=92.4 \AA, c=145.0 \AA$ ) grew in two days at $18^{\circ} \mathrm{C}$ from $4 \mu \mathrm{l}$ hanging drops containing $20 \mathrm{mg} \mathrm{ml}^{-1}$ protein, $100 \mathrm{mM}$ Tris- $\mathrm{HCl}$ (pH 7.5), $100 \mathrm{mM} \mathrm{KCl}$, and $25 \%$ saturated ammonium sulfate when equilibrated over a reservoir containing the same solution with 50\% saturated ammonium sulfate and no protein. Before data collection, crystals were "washed" for one minute in a cryosolvent that contained $25 \%(\mathrm{w} / \mathrm{w})$ sucrose and all the reservoir components except that the ammonium sulfate concentration was increased to 55\% saturated. Washed crystals were mounted in nylon loops, and flash frozen in liquid propane cooled to near liquid nitrogen temperature. Frozen crystals embedded in solid propane were stored in liquid nitrogen until exposure to X-rays in a nitrogen stream at $100 \mathrm{~K}$. These crystals contained two molecules in the asymmetric unit and diffracted to $3.0 \AA$ on laboratory sources and to at least $2.2 \AA$ using synchrotron radiation (Table 1). The mercury derivative was prepared by soaking the crystals in stabilizer (reservoir solution with $55 \%$ saturated ammonium sulfate) and $1 \mathrm{mM} \mathrm{HgCl} 2$ for 12 hours. All data were processed using DENZO and SCALEPACK (Otwinowski, 1993). Two mercury sites per monomer were found by applying the direct methods algorithm of the program SHELXS-86 (Sheldrick, 1990) to the isomorphous differences between parent data set 2 and the mercury data set. One selenium site per monomer was located from isomorphous difference Fouriers using the phases derived from the mercury derivative. Heavy-atom parameters were refined and phases computed with MLPHARE (Otwinowski, 1991). The initial map was used to define the orientation and position of the non-crystallographic 2-fold symmetry axis and then improved by molecular averaging. To improve the quality of the map, solvent flattening and histogram matching was performed using the program DPHASE (G. Van Duyne). The resulting map allowed easy fitting of the major secondary structural elements. The model was completed after iterative cycles of partial model refinement and phase combination. Selenium sites corresponded to methionine sulfur positions providing an internal check of the sequence assignment. The model was built using the program $\mathrm{O}$ (Jones et al., 1991) and the structure was refined with X-PLOR (Brünger, 1993) using simulated annealing, conjugate gradients minimization and constrained $B$ factor refinement with data from parent data set 1 at a resolution range of 6.0 to $2.2 \AA$. The current model includes 183 out of the 191 amino acid residues per molecule and 268 water molecules in the asymmetric unit. Average $B$-factor for all non-hydrogen protein atoms is $42 \AA^{2}$, consistent with the Wilson plot analysis of the diffraction data. No residues have $\phi, \psi$ angles in disallowed regions. The current model is refined to an $R$-factor of 0.205 (free $R$-factor $=0.285$ ), for data with $|F|>2 \sigma$ and Bragg spacings of 6.0 to $2.2 \AA$. The $\mathrm{N}$-terminal methionine and the $\mathrm{C}$-terminal acidic tail consisting of six glutamic acids (residues 185 to 190) and leucine (191) were not represented in $\left(2\left|F_{\mathrm{o}}\right|-\left|F_{\mathrm{c}}\right|\right)$ maps for both molecules in the asymmetric unit. Both molecules were refined independently and have a RMSD between $\mathrm{C}^{\alpha}$ atoms of $0.7 \AA$.

\section{Gel filtration}

Gel filtration was performed to determine if the PwTBP forms a dimer in solution, similar to the behavior of the eukaryotic homologs. PwTBP $(200 \mu \mathrm{M})$ was dialyzed against $40 \mathrm{mM}$ potassium phosphate ( $\mathrm{pH}$ 7.0). $100 \mu \mathrm{l}$ of protein sample $\left(0.25 A_{280}\right)$ was injected onto a Pharmacia Superdex 75 gel filtration column $(16 \mathrm{~mm}$ diameter, $60 \mathrm{~cm}$ length) previously equilibrated with the same buffer, and then run with a flow rate of $1 \mathrm{ml} / \mathrm{min}$. For determination of molecular volume the elution profile was compared to molecular weight standards (BioRad) and ScTBPc.

\section{Differential scanning calorimetry}

Differential scanning calorimetry was used to determine the unfolding transition temperatures of Sc TBPc and PwTBP. Sc TBPc was prepared as described (J. L. Kim et al., 1993). Protein samples $(60 \mu \mathrm{M})$ were dialyzed overnight into the various buffer conditions (Figure 6). Differential scanning calorimetry measurements were carried out with the DASM-4 instrument (Biopribor, Puschino, Moscow Region, Russia: Privalov, 1980) at a scan rate of $1 \mathrm{~K} / \mathrm{min}$. The reference cell was filled with solvent and the instrumental baselines were determined with solvent filling both cells. All samples were visibly precipitated after denaturation and rescanning of the samples indicated that the thermal denaturation process was irreversible. Thus, the equilibrium thermodynamic parameters could not be derived from these data. 


\section{Packing calculation}

Analysis of atomic packing for protein structures was performed using an extension of the occluded surface analysis described previously (Pattabiraman et al., 1995). In this method, a molecular dot surface of each residue is calculated with a $1.4 \AA$ probe using the MS program of Connolly (1985). A normal is extended radially from each dot until it either intersects the van der Waals surface of a neighboring atom or reaches a length of $2.8 \AA$ (the diameter of a water molecule). Occluded surface, $O S$, is that molecular surface area on the originating atom associated with normals that intersect with another atom as opposed to reaching the $2.8 \AA$ limit, all other molecular surface area is considered non-occluded. The packing value, $P V_{\text {res, }}$ for each residue is defined as:

$$
P V_{\text {res }}=\frac{\sum_{\text {atom }}^{\text {res }}\left[O S_{\text {atom }}\langle 1-P P\rangle_{\text {atom }}\right]}{T S_{\text {res }}}
$$

where $T S_{\text {res }}$ is total molecular surface of the residue (sum of occluded and non-occluded areas) and $P P$ is the length (maximum $=2.8$ ) of the normal divided by 2.8. For example the $P V_{\text {res }}$ of a completely non-occluded residue (100\% "exposed") equals zero, and the mean $P V_{\text {res }}$ for the three residues in tightly packed crystalline Gly-Phe-Gly is 0.571 . The mean protein packing value reported in Figure 7 is the mean $P V_{\text {res }}$ for each protein.

\section{Acknowledgements}

This work was supported in part by a National Institutes of Health grant to P.B.S. (GM15225). B.S.D. was an NIH predoctoral trainee (GM07223). Work in the S.P.J. laboratory was funded by grants from the Medical Research Council (UK) and the Leverhulme trust. We thank Professor J. M. Sturtevant (Yale University) for support and access to the DASM- 4 differential scanning calorimeter and Microcal titration calorimeter. Work in the J.M.S. laboratory was funded by National Institutes of Health grant GM04725.

\section{References}

Adams, M. W. W. (1993). Enzymes and proteins from organisms that grow near and above $100^{\circ} \mathrm{C}$. Annu. Rev. Microbiol. 47, 627-658.

Barlow, D. J. \& Thornton, J. M. (1983). Ion-pairs in proteins. J. Mol. Biol. 168, 867-885.

Brünger, A. T. (1992). The free R value: a novel statistical quantity for assessing the accuracy of crystal structures. Nature, 355, 472-474.

Brünger, A. T. (1993). XPLOR Version 3.1: A System for $X$-ray Crystallography and $N M R$. Yale University Press, New Haven.

Bucher, P. (1990). Weight matrix descriptions of four eukaryotic RNA polymerase II promoter elements derived from 502 unrelated promoter sequences. J. Mol. Biol. 212, 563-578.

Bult, C. J., White, O., Olsen, G. J., Zhou, L., Fleischmann, R. D., Sutton, G. G., Blake, J. A., FitzGerald, L. M. \& Clayton, R. A. (1996). Complete genome sequence of the methanogenic archaeon, Methanococcus jannaschii. Science, 273(5278), 1058-1073.

Carson, M. (1991). Ribbons 2.0. J. Appl. Crystallog. 24, 958-961.
Chan, M. K., Mukund, S., Kletzin, A., Adams, M. W. W. \& Rees, D. C. (1995). Structure of a hyperthermophilic tungstopterin enzyme, aldehyde ferredoxin oxidoreductase. Science, 267, 1463-1469.

Chasman, D. I., Flaherty, K. M., Sharp, P. A. \& Kornberg, R. D. (1993). Crystal structure of yeast TATA-binding protein and model for interaction with DNA. Proc. Natl Acad. Sci. USA, 90, 8174-8178.

Coleman, R. A., Taggart, A. K. P., Benjamin, L. R. \& Pugh, B. F. (1995). Dimerization of the TATA binding protein. J. Biol. Chem. 270, 13842-13849.

Connolly, M. L. (1985). Computation of molecular volume. J. Am. Chem. Soc. 107(5), 1118-1124.

Day, M. W., Hsu, B. T., Joshua-Tor, L., Park, J.-B., Zhou, Z. H., Adams, M. W. W. \& Rees, D. C. (1992). X-ray crystal structures of the oxidized and reduced forms of the rubredoxin from the marine hyperthermophilic archaebacterium Pyrococcus furiosus. Protein Sci. 1, 1494-1507.

Dill, K. A. \& Shortle, D. (1991). Denatured states of proteins. Annu. Rev. Biochem. 60, 795-825.

Forterre, P. (1996). A hot topic: the origin of hyperthermophiles. Cell, 85, 789-792.

Geiger, J., Hahn, S., Lee, S. \& Sigler, P. B. (1996). Crystal structure of the yeast TFIIA/TBP/DNA complex. Science, 272, 830-836.

Genetics Computer Group (1994). Wisconsin Package, 8th edit., Madison, Wisconsin.

Hahn, S., Buratowski, S., Sharp, P. A. \& Guarente, L. (1989). Yeast TATA-binding protein binds to TATA elements with both consensus and nonconsensus DNA sequences. Proc. Natl Acad. Sci. USA, 86, 5718-5722.

Hennig, M., Darimont, B., Sterner, R., Kirschner, K. \& Jansonius, J. N. (1995). $2.0 \AA$ structure of indole-3gycerol phosphate synthase from the hyperthermophile Sulfolobus solfataricus: possible determinats of protein stability. Structure, 3, 1295-1306.

Jones, T. A., Zou, J. Y., Cowan, S. W. \& Kjeldgaard, M. (1991). Improved methods for building protein models in electron density maps and the location of errors in these models. Acta Crystallog. sect. A, 47, 110-119.

Kabsch, W. \& Sander, C. (1983). Dictionary of protein secondary structure: pattern recognition of hydrogen-bonded and geometrical features. Biopolymers, 22, 2577-2637.

Kim, J. L., Nikolov, D. B. \& Burley, S. K. (1993). Co-crystal structure of TBP recognizing the minor groove of a TATA element. Nature, 365, 520-527.

Kim, Y., Geiger, J. H., Hahn, S. \& Sigler, P. B. (1993). Crystal structure of a yeast TBP/TATA-box complex. Nature, 365(7), 512-520.

Korndörfer, I., Steipe, B., Huber, R., Tomschy, A. \& Jaenicke, R. (1995). The crystal structure of hologlyceraldehyde-3-phosphate dehydrogenase from the hyperthermophilic bacterium Thermotoga maritima at $2.5 \AA$ resolution. J. Mol. Biol. 246, 511-521.

Kosa, P., Ghosh, G., DeDecker, B. S. \& Sigler, P. B. (1996). Structural analysis of the TBP/TFIIB/DNA complex from the hyperthermophilic Archaea Pyrococcus woesei. Abstract no. 328. In Keystone Symposia (Transcriptional Mechanisms), Taos, New Mexico.

Lee, B. \& Richards, F. M. (1971). The interpretation of protein structures: estimation of static accessibility. J. Mol. Biol. 55, 379-400.

Lee, W. S., Kao, C. C., Bryant, G. O., Liu, X. \& Berk, A. J. (1991). Adenovirus E1A activation domain binds the 
basic repeat in the TATA box transcription factor. Cell, 67, 365-376.

Liu, X., Miller, C. W., Koeffler, P. H. \& Berk, A. J. (1993). The p53 activation domain binds the TATA box-binding polypeptide in holo-TFIID, and a neighboring p53 domain inhibits transcription. Mol. Cell Biol. 13(6), 3291-3300.

Marsh, T. L., Reich, C. I., Whitelock, R. B. \& Olsen, G. J. (1994). Transcription factor IID in the Archae: sequences in the Thermococcus celer genome would encode a product closely related to the TATA-binding protein of eukaryotes. Proc. Natl Acad. Sci. USA, 91, 4180-4184.

Miller, S., Janin, J., Lesk, A. M. \& Chothia, C. (1987). Interior and surface of monomeric proteins. J. Mol. Biol. 196, 641-656.

Nicholls, A., Bharadwaj, R. \& Honig, B. (1993). GRASP: graphical representation and analysis of surface properties. Biophys. J. 64, part 2, A166.

Nikolov, D. B. \& Burley, S. K. (1994). $2.1 \AA$ Å resolution refined structure of a TATA box-binding protein (TBP). Nature Struct. Biol. 1(9), 621-637.

Nikolov, D. B., Hu, S.-H., Lin, J., Gasch, A., Hoffmann, A., Horikoshi, M., Chua, N.-H., Roeder, R. G. \& Burley, S. K. (1992). Crystal structure of TFIID TATA-box binding protein. Nature, 360, 40-46.

Nikolov, D. B., Chen, H., Halay, E. D., Usheva, A. A., Hisatake, K., Lee, D. K., Roeder, R. G. \& Burley, S. K. (1995). Crystal structure of a TFIIB-TBP TATAelement ternary complex. Nature, 377, 119-128.

Otwinowski, Z. (1991). ML-PHARE CCP4 Proc 80-88, Daresbury Laboratory, Warrington, UK.

Otwinowski, Z. (1993). In Data Collection and Processing, Warrington, England.

Pace, C. N., Vajdos, F., Fee, L., Grimsley, G. \& Gray, T. (1995). How to measure and predict the molar adsorption coefficient of a protein. Protein Sci. 4, 2411-2423.

Palmer, J. R. \& Daniels, C. J. (1995). In vivo definition of an archaeal promoter. J. Bacteriol. 177(7), 1844-1849.

Pattabiraman, N., Ward, K. B. \& Fleming, P. J. (1995). Occluded molecular surface: analysis of protein packing. J. Mol. Recognit. 8, 334-344.

Petri, V., Hsieh, M. \& Brenowitz, M. (1995). Thermodynamic and kinetic characterization of the binding of the TATA binding protein to the adenovirus E4 promoter. Biochemistry, 34(31), 9977-9984.

Privalov, P. L. (1980). Scanning microcalorimeters for studying macromolecules. Pure Appl. Chem. 52, 479-497.
Qureshi, S. A., Baumann, P., Rowlands, T., Khoo, B. \& Jackson, S. P. (1995a). Cloning and functional analysis of the TATA binding protein from Sulfolobus shibatae. Nucl. Acids Res. 23(10), 1775-1781.

Qureshi, S. A., Khoo, B., Baumann, P. \& Jackson, S. P. (1995b). Molecular cloning of the transcription factor TFIIB homolog from Sulfolobus shibatae. Proc. Natl Acad. Sci USA, 92, 6077-6081.

Rashin, A. A., Iofin, M. \& Honig, B. (1986). Internal cavities and buried waters in globular proteins. Biochemistry, 25(12), 3619-3625.

Richards, F. M. (1974). The interpretation of protein structures: total volume, group volume distributions and packing density. J. Mol. Biol. 82, 1-14.

Richards, F. M. \& Lim, W. A. (1994). An analysis of packing in the protein folding problem. Quart. Rev. Biophys. 26(4), 423-498.

Rowlands, T., Baumann, P. \& Jackson, S. P. (1994). The TATA-binding protein: a general transcription factor in eukaryotes and Archaebacteria. Science, 264, 1326-1329.

Scholz, S., Sonnenbichler, J., Schäfer, W. \& Hensel, R. (1992). Di-myo-inositol-1,1'-phosphate: a new inositol phosphate isolated from Pyrococcus woesei. FEBS Letters, 306(2,3), 239-242.

Sheldrick, G. M. (1990). Phase annealing in Shelx-90: direct methods for larger structures. Acta Crystallog. 46, 467-473.

Tan, S., Hunziker, Y., Sargent, D. F. \& Richmond, T. J. (1996). Crystal structure of a yeast TFIIA/TBP/DNA complex. Nature, 381, 127-134.

Woese, C. R. (1987). Bacterial evolution. Microbiol. Rev. 221-271.

Woese, C. R., Kandler, O. \& Wheelis, M. L. (1990). Towards a natural system of organisms: proposal for the domains Archae, Bacteria, and Eucarya. Proc. Natl Acad. Sci. USA, 87, 4576-4579.

Yip, K. S. P., Stillman, T. J., Britton, K. L., Artymiuk, P. J., Baker, P. J., Sedelnikova, S. E., Engel, P. C., Pasquo, A., Chiaraluce, R., Consalvi, V., Scandurra, R. \& Rice, D. W. (1995). The structure of Pyrococcus furiosus glutamate dehydrogenase reveals a key role for ion-pair networks in maintaining enzyme stability at extreme temperatures. Structure, 3, 1147-1158.

Zillig, W., Palm, P., Klenk, H.-P., Langer, D., Hüdepohl, U., Hain, J., Lanzendörfer, M. \& Holz, I. (1993). Transcription in archaea. In The Biochemistry of Archaea (Archaebacteria) (Kates, M., Kushner, D. J. \& Matheson, A. T., eds), vol. 26, pp. 367-386, Elsevier, Amsterdam.

Edited by I. A. Wilson

(Received 17 July 1996; received in revised form 14 October 1996; accepted 14 October 1996)

Note added in proof: The conclusion, that if an archaeal TFIIA were to exist, then it would have to have a radically different TBP binding surface, was confirmed by the sequence of the complete genome of Methanococcus jannaschii (Bult et al., 1996). The genome of this archaeal species contains no obvious homologs of TFIIA. 